\title{
Pycnodysostosis
}

\section{A Variant Form with Visceral Manifestations}

\author{
K. KOZLOWSKI and J. S. YU \\ From the Department of Radiology, Royal Alexandra Hospital for Children, and Department of Child Health, \\ University of Sydney
}

\begin{abstract}
Kozlowski, K., and Yu, J. S. (1972). Archives of Disease in Childhood, 47, 804. Pycnodysostosis: a variant form with visceral manifestations. The history of a 3-year-old boy is presented who has clinical and radiological features of pycnodysostosis. He also suffers from haematological and visceral complications suggestive of osteopetrosis, which have not previously been described in pycnodysostosis. This variant form of dense bone disease appears to provide the clinical link between pycnodysostosis and osteopetrosis and shows yet another example of phenotypic and perhaps genotypic heterogeneity in metabolic diseases.
\end{abstract}

Genetic heterogeneity is now widely recognized and in the inborn errors of metabolism provides a rational explanation for the varied clinical and biochemical picture that is seen within a disease syndrome; indeed many metabolic diseases are now recognized to be a group of diseases rather than a single entity.

In 1904, Albers-Schönberg described marblebone disease or osteopetrosis and subsequently two forms were recognized, a precocious form (malignant in the old terminology) and one with delayed manifestations (Silverman, 1971). Several distinct clinical and radiological entities were differentiated from osteopetrosis as a result of the more widespread use of radiographic examinations. Another distinct variant was reported in 1962 by Maroteaux and Lamy and called pycnodysostosis. This variant is characterized clinically by short stature, short hands and feet, mandibular hypoplasia, delayed closure of the fontanelles with separated cranial sutures, and a tendency to fracture. Like osteopetrosis, the bones are dense, but pycnodysostosis lacks the visceral and haematological features of osteopetrosis. This report describes a 3-year-old boy who was mistakenly diagnosed as osteopetrosis and included in a study of osteopetrosis published last year in this journal (Yu et al., 1971).

On reviewing his $x$-ray films and subsequent progress, he has the classical radiological features of pycnodysostosis, but his clinical picture is complicated by the visceral and haematological

Received 13 March 1972. changes seen in osteopetrosis with precocious manifestations.

\section{Case Report}

The patient was previously reported (Case 1) in a study of osteopetrosis in this journal (Yu et al., 1971). He presented at 5 months of age with hepatomegaly and was found to have a clinical picture consistent with osteopetrosis of the precocious type. Attempts were made to achieve a negative calcium balance with a low calcium diet and cellulose phosphate but prednisone had to be given to control his haemolytic anaemia.

His clinical progress was satisfactory and his laboratory studies well controlled until 26 months of age when his serum alkaline phosphatase rose to 39 King-Armstrong units per $100 \mathrm{ml}$ and $x$-rays showed evidence of rickets. Vitamin D 400 units was added to his diet.

$\mathrm{He}$ is now 3 years old and his fontanelle is still open. His weight and height are now just below the 3rd centile and his biochemical and haematological picture remain static. Any attempts to reduce his prednisone intake result in a haematological relapse. He is bilingual and is now developmentally normal.

In October 1971 his $x$-rays were reviewed by one of us (K.K.) and features highly suggestive of pycnodysostosis found (see Fig. 1-6); the original diagnosis of osteopetrosis was questioned.

\section{Discussion}

Although the clinical picture of pycnodysostosis may be suggestive, it is the radiographic findings which are decisive in establishing the diagnosis. Diagnostic radiological features include moderate generalized osteosclerosis, disappearance of the mandibular angle, aplasia of the terminal phalanges, 

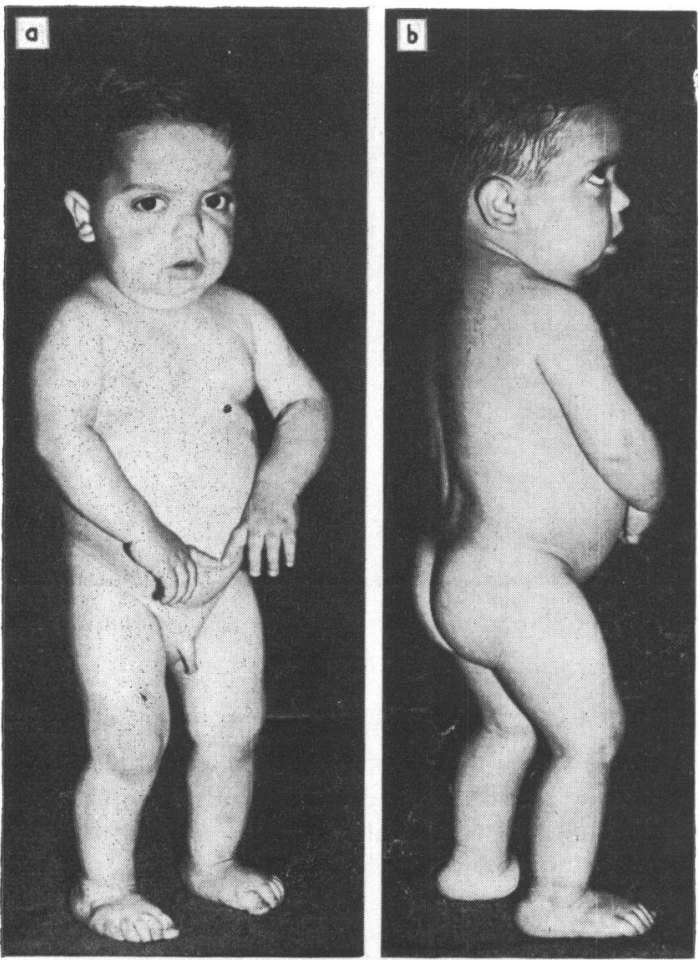

FIG. 1.-Photographs of the patient at the age of 3 years.

(a) Anteroposterior and (b) lateral projections showing high frontal and occipital prominence of the skull and hypoplastic mandible.

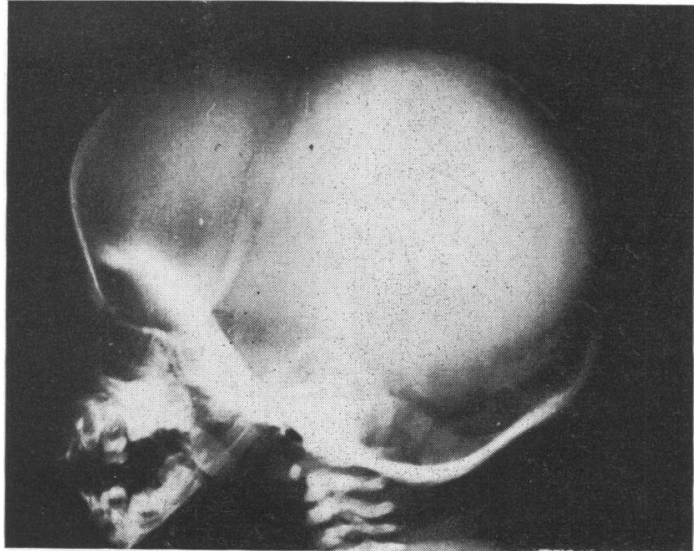

FIG. 2.-Skull at 3 years. The bones are dense. The fontanelles are widely open and the cranial sutures are large. The calvarium is large in relation to the facial bones and the mandibular angle is abolished. There is bossing of the frontal bones and an absence of pneumatization of the mastoid processes.
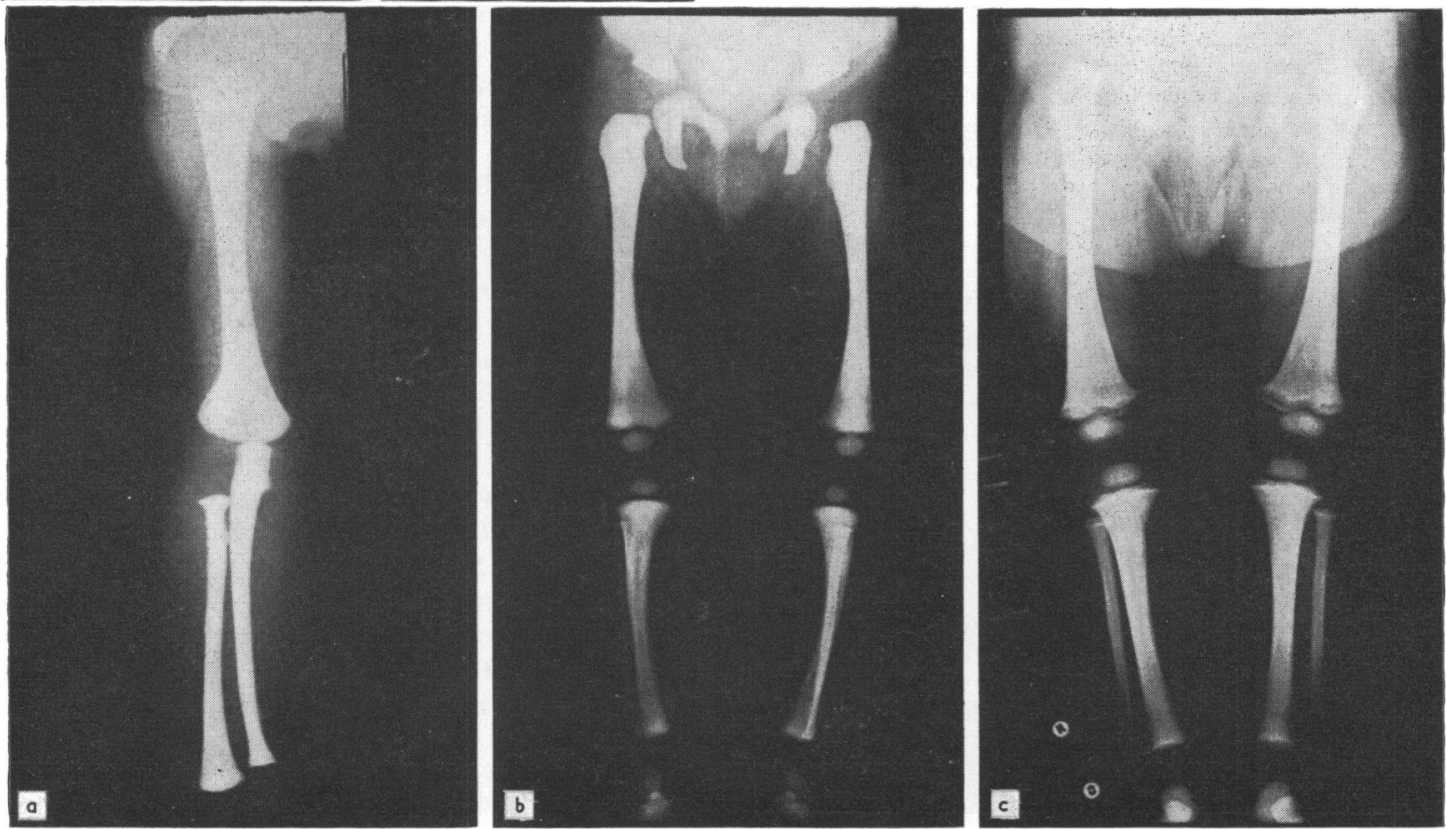

FIG. 3.-The long bones are thin but of increased density. (a) Left upper extremity at 7 months. There is proximal shortening of radius and distal shortening of ulna. (b) Lower limbs at 7 months of age. There is normal modelling. (c) Lower limbs at 26 months of age and after 15 months' treatment. The density of the bones is somewhat decreased and there are definite changes of rickets (the metaphysial areas are spread, fragmented, and cupped). 


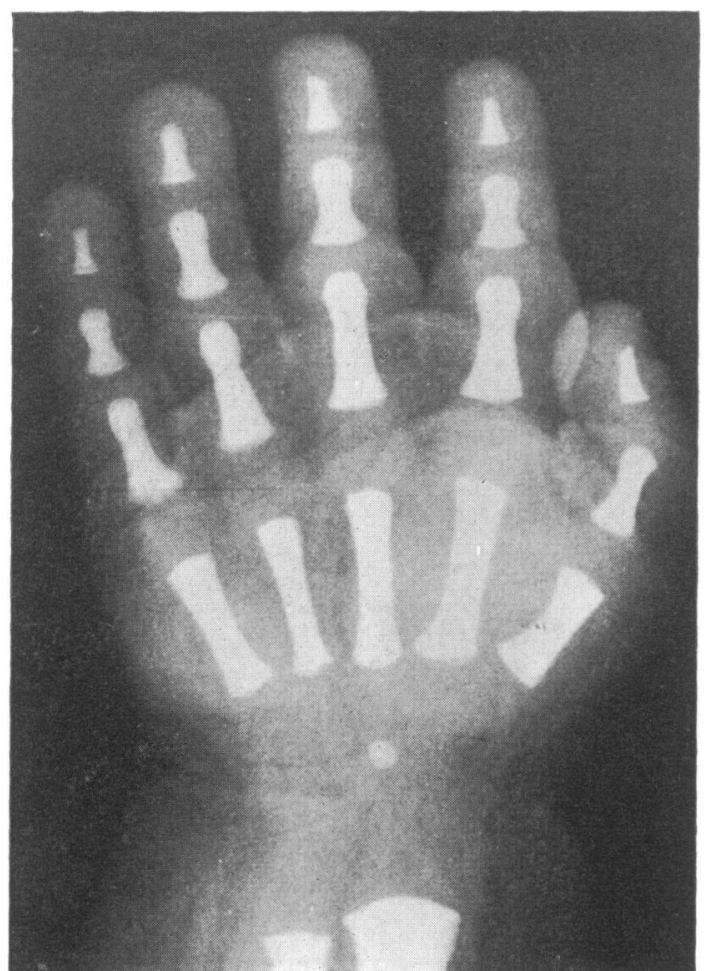

Fig. 4.-Hand at 7 months of age. The bones are dense but thin and somewhat shortened. The osteolytic changes are seen at the distal phalanges. Bone age corresponds to a chronological age of about 3 months.

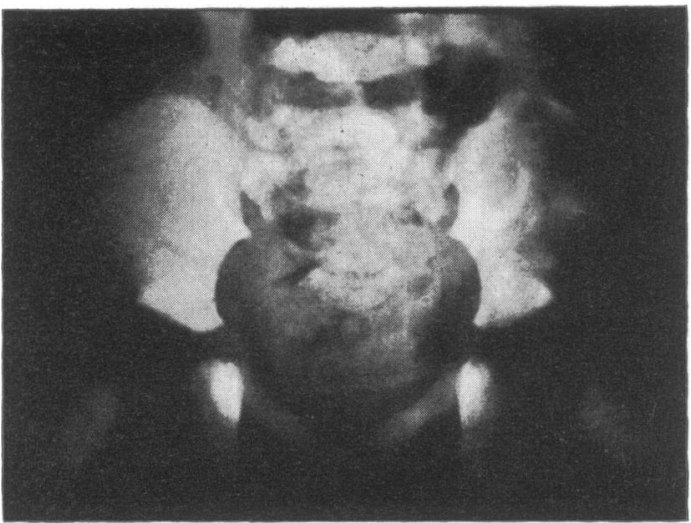

FIG. 5.-Pelvis at 7 months of age. Slight supraacetabular constriction. This was more marked at the examination 1 year later. No ossification centres of the femoral heads are present.

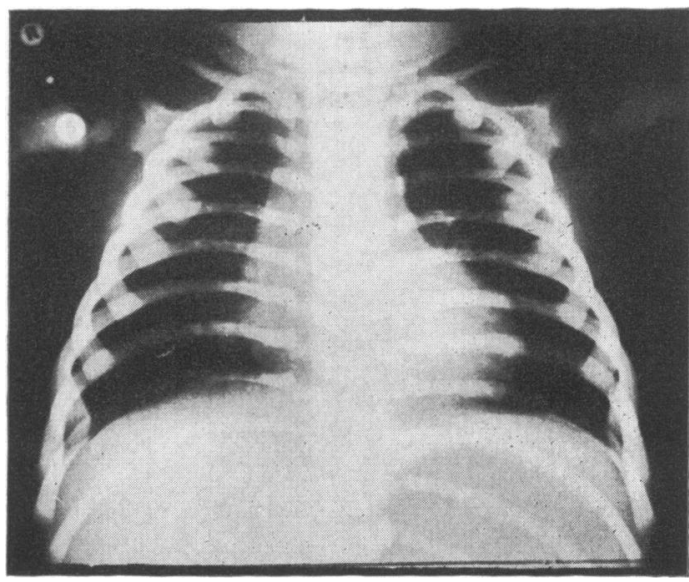

FIG. 6.-Chest at 7 months showing the hypoplastic and thin clavicles.

clavicular hypoplasia, and thin tubular long bones. In adults the absence of paranasal pneumatization, secondary bowing of the radius due to overgrowth, spoon-shaped vertebral bodies, and transverse fractures following relatively mild trauma are additional findings.

In infancy, classical osteopetrosis with precocious manifestations shows increased bone density and poor modelling of the long bones. The bones often show alternating bands of varying density. The specific radiological features of pycnodysostosis are not seen.

In the differential diagnosis, osteopetrosis, dysosteosclerosis, and cleidocranial dysplasia should be considered. The precocious type of osteopetrosis follows a progressive course, with death usually occurring in infancy or early childhood. A progressive anaemia and neurological defects are constant findings in the precocious form of osteopetrosis. Radiologically the density of the bones is more marked in osteopetrosis than in pycnodysostosis and there is hypotubulation of the ends of the shafts with parallel, alternating lines of increased and decreased density; a finding never observed in pycnodysostosis. The mandibular angle may be diminished in osteopetrosis, but is not abolished and the anterior fontanelle never persists. No clavicular and distal phalangeal dysplasia is present.

Short stature is a feature of pycnodysostosis and adults reach about $153 \mathrm{~cm}$ (5 feet) in height. The sex distribution is equal and the ethnic origin is without significance. Dysosteosclerosis (Spranger et al., 1968) is also characterized by small stature, but there is also increased bone fragility, dysodonty, 
and involvement of the cranial nerves. The radiographic picture includes a combination of osteosclerotic and osteodysplastic changes in the long bones similar to those found in Pyle's disease, with platyspondylia and inconstant hypoplasia of the iliac bones.

The patients with cleidocranial dysplasia are generally mildly to moderately short. The density of the bones is normal or decreased, and there are characteristic changes in the skull and pelvis as a result of the delayed and deficient ossification. The mandible angle is normal. The clavicular hypoplasia is usually medial, but the pattern of the defect may vary from complete agenesis to partial hypoplasia or even normal clavicles. We do not believe that other, specifically osteosclerotic, bone diseases should cause difficulties in the differential diagnosis.

The unusual findings in our patient are the hepatosplenomegaly and anaemia. No cases of pycnodysostosis with these findings have been reported (Shuler, 1963; Elmore, 1967). Hepatosplenomegaly and anaemia are, of course, characteristic of osteopetrosis. This boy then has the classical radiological findings of pycnodysostosis, but the typical clinical presentation of infantile osteopetrosis, and provides the unifying link between these two poles of the condensing bone disease spectrum.

The clinical progress in our patient is confused by the therapy which aimed at producing a negative calcium balance, and by the development of rachitic changes. The rachitic changes are almost certainly the result of the zealous pursuit of this therapy. Problems in performing a formal calcium balance study have prevented documentary proof of a negative calcium balance. The early onset of symptoms, however, is suggestive that, without treatment, this infant may have followed the clinical course of osteopetrosis of precocious onset and may have succumbed at an early age.

The histological appearance of bone is identical in osteopetrosis and pycnodysostosis (Shuler, 1963; Elmore et al., 1966); however, in the latter disease there is a small and imperfect medullary canal and microscopical evidence of haemopoiesis. Biochemical studies, so far reported, have been normal in both. The other bone changes in pycnodysostosis, however, suggest that the differences are greater than can be explained on simple quantitative lines. The basic defect in osteopetrosis, in either form, has not been elucidated, though the bone-inbone appearance, which is sometimes seen in the long bones of hands and feet, and the positive calcium balance (Dent, Smellie, and Watson, 1965) suggest some defect in bone reabsorption rather than a primary abnormality in mineralization.

It would be wrong, however, to expect that the same biochemical anomaly is the underlying factor in all the diseases of the condensing bone syndrome. The inheritance of osteopetrosis (Johnston et al., 1968) suggests that the late and precocious forms are distinct diseases. Such a distinction, however, does not exclude the possibility of either multiple alleles or the effect of modifying genes. This infant, by widening the clinical spectrum of pycnodysostosis, lends some support to the thesis that osteopetrosis and pycnodysostosis are related in a way more complex than the morphological similarity of increased radiographic bone density.

\section{REFERENCES}

Albers-Schönberg, H. (1904). Röntgenbilder einer seltenen Knochenerkrankung. Münchener medizinische Wochenschrift, 51, $36 \overline{5}$.

Dent, C. E., Smellie, J. M., and Watson, L. (1965). Studies in osteopetrosis. Archives of Disease in Childhood, 40, 7.

Elmore, S. M. (1967). Pycnodysostosis: a review. Fournal of Bone and foint Surgery, 49A, 153.

Elmore, S. M., Nance, W. E., McGee, B. J., Engel-De Montmollin, M., and Engel, E. (1966). Pycnodysostosis, with a familial chromosome anomaly. American fournal of Medicine, 40, 273.

Johnston, C. C., Jr., Lavy, N., Lord, T., Vellios, F., Merritt, A. D., and Deiss, W. P., Jr. (1968). Osteopetrosis. Medicine, 47, 149.

Maroteaux, P., and Lamy, M. (1962). Deux observations d'une affection osseuse condensante: la pycnodysostose. Archives Françaises de Pédiatrie, 19, 267.

Shuler, S. E. (1963). Pycnodysostosis. Archives of Disease in Childhood, 38, 620.

Silverman, F. N. (1971). Nomenclature for constitutional (intrinsic) diseases of bones. Pediatrics, 47, 431.

Spranger, J., Albrecht, C., Rohwedder, H. J., and Wiedemann, H. R. (1968). Die Dysosteosklerose: eine Sonderform der generalisierten Osteosklerose. Fortschritte auf dem Gebiete der Roentgenstrahlen und der Nuklearmedizin, 109, 504.

Yu, J. S., Oates, R. K., Walsh, K. H., and Stuckey, S. J. (1971). Osteopetrosis. Archives of Disease in Childhood, 46, 257.

Correspondence to Dr. J. S. Yu, Department of Medicine, Royal Alexandra Hospital for Children, Camperdown, N.S.W. 2050, Australia. 